\section{On Introducing Students To Some Contributions Of Mathematical Knowledge To The Victory Of The World War II}

\author{
R.M. Turgunbayev, \\ Candidate of Physical and Mathematical Sciences, Associate \\ Professor, \\ Acting Professor of Tashkent State Pedagogical University, \\ Uzbekistan
}

\author{
G.R. Muxamedova \\ Candidate of Pedagogical Sciences, Associate Professor, \\ Tashkent State Pedagogical University, Uzbekistan
}

\author{
G open ACCESS \\ The American Journal of \\ Social Science And \\ Education Innovations \\ JULY 2020 \\ Page No.: 71-75 \\ Volume-II Issue-VII \\ PUBLISHED: 30 JULY 2020 \\ www.usajournalshub.com/inde \\ x.php/tajssei \\ Copyright: Original content \\ from this work may be used \\ under the terms of the \\ Creative Commons Attribution \\ 4.0 licence.
}

\begin{abstract}
Mathematics is not just a science of numbers and figures, it is a science of history, of human destiny. Mathematicians give machine builders and architects, physicists and chemists, biologists and economists, and even the military a number of methods for studying complex processes. The article discusses the contribution of mathematicians to the victory over the enemy in World War II.
\end{abstract}

Keywords: history of mathematics, World War II, mathematics, mathematicians, competence.

\title{
Introduction
}

Teaching math in school also means teaching these students about the history of mathematics, as any subject is based on knowledge gained from previous generations. Without studying them, it is difficult to understand all the new things that are happening in mathematics and other sciences.

The task of the history of mathematics is not only to provide information about the scientific heritage of famous scientists, the formation and development of mathematical ideas, concepts, methods, but also to show that the development of mathematics is related to solving pressing issues of life.

By coordinating the study of mathematics with other disciplines, emphasizing the role and influence of practice in the development of mathematics, and showing the conditions and sometimes the reasons for the emergence and formation of concepts, methods, we thus help to develop. The role of historical and mathematical materials in the 
formation of interest in the subject, the education of worldviews, the moral qualities of the individual, the solution of problems such as patriotism is well known.

The use of historical data in the formation of students' core competencies in mathematics lessons is useful. However, there is still no comprehensive teaching and methodological assistance to realize the potential of historical and mathematical content in the education of schoolchildren.

In the scientific methodical literature [1.56] the following forms of disclosure of historical and mathematical content are recommended: teacher's story, historical excursion, introduction to the topic, part of the lecture, assignments with historical plot, heuristic conversation, seminar, student information and lectures, school student research, student projects, school lecture work, competitions, math evenings, math newspapers, conferences, etc.

In the above-mentioned forms of training, students learn not only about mathematics and its applications, but also about the basic competencies (communicative, information work, self-development, social activism) in the students involved in the organization of the event (civic, national and intercultural) formation, allows the formation of cognitive competencies in the participants of the event.

Therefore, in order to take full advantage of the available opportunities, it is advisable to organize math evenings, conferences, competitions, conversations, math posters dedicated to various famous dates.

In this article, we provide some of the contributions of mathematicians to victory behind the front lines that can be used in mathematical events dedicated to the 75th anniversary of World War II.

\section{The Main Findings And Results}

We must bow to the courage, self-sacrifice and devotion of the people who fought against fascism in World War II, especially the mathematicians and warriors. But we must not forget the other contribution of mathematicians to the victory over the enemy. It is the use of mathematical knowledge and skills. The importance of this factor is especially important in our time, when the war is manifested, first of all, as a race of consciousness, invention and accurate calculations. The point is that all the achievements of the natural sciences, especially mathematics, are involved in combat operations. As evidence for this, we cite the following.

a) As you know, artillery cannot survive without accounting. The issue of gunfire dates back to the 19th century. But the advent of warplanes and tanks has prompted further firing. In particular, the problem of airborne and ground launches has led to mathematical problems, which have been addressed by mathematicians as well as artillery experts. Problems in the theory of bombardment have led to the need to create tables that allow to determine the optimal time for bombing the target, the diameter of the area covered by the bomb. Such schedules were made before the outbreak of World War II, but they were designed for high-speed aircraft. During the war, special regiments of lowspeed and silent bombers were formed, for which no such schedules were drawn up. The Department of Probability Theory at Moscow State University has developed such tables for bombing small planes from low altitudes and low speeds. These tables helped the pilots tremendously [2. 10-17]. 
b) The great mathematician, academician A.N. Kolmogorov, using his work on the theory of probability, developed the most useful theory of the distribution of artillery shells. The mathematical essence of this problem is that when you shoot an object $A$ on the ground, in general, the projectiles do not hit the target clearly, but scatter around. AN Kolmogorov found a complete solution to this problem and brought it to the level of implementation. The results obtained helped to increase the firing rate and at the same time increase the efficiency of artillery operations [3.192].

c) In April 1942, a team of mathematicians led by Academician S.N. Bernstein developed charts to determine the location of a ship based on radio findings. These tables allowed navigators to speed up their calculations by 10 times. Developed in 1943, these tables have been used effectively in long-range aviation military operations. The former Soviet aviation headquarters praised the work of mathematicians, noting that no other country had such a simple and wonderful table.

d) The development of nomography - a branch of mathematics that studies the theory and methods of drawing diagrams, called time-saving and simplifying nomograms has played an important role in solving practical problems, including practical problems in defense. The nomograms, developed by a special bureau headed by N.A. Glagolev, were used by the navy and anti-aircraft artillery to protect cities from enemy air attack.

e) During World War II, technology was diverse and complex. Therefore, its production and operation required a wide range of mathematical calculations.

In order to increase the flight speed of the aircraft, it was necessary not only to increase the engine power, but also to solve many problems, such as the optimal choice of the overall appearance of the fuselage and wings. The solution of these problems has allowed aircraft designers to achieve brilliant results in the development of military aircraft. But in addition to achieving high speeds of aircraft, aircraft designers have encountered unprecedented events in the flight of aircraft. During certain engine modes, high-amplitude motions would occur spontaneously in the structures, causing the plane (flatter) to crash in the air. Flatter was a word that terrified test pilots in the pre-war years [2. 10.17].

The same situation was observed in fast-moving cars on the ground. During takeoff and landing, the plane's wheels spun from side to second side. This condition, called shimmy, is one of the most common causes of plane crashes at airports. The famous mathematician M. V. Keldish and a team of scientists led by him studied the causes of flatter and shimmy phenomena. The mathematical theory of these dangerous phenomena, developed by scientists, has allowed aviation science to prevent such vibrations of highspeed aircraft in a timely manner. Scientists have made recommendations that should be taken into account when designing aircraft. As a result, the number of plane crashes during the war due to inaccurate calculations has been eliminated.

American mathematician T. Fon Karman analyzed aerodynamics, turbulence phenomena and gave advice to the American aviation military [4].

f) It is impossible not to mention another contribution of mathematicians to the front - the work done to improve the efficiency of production and the organization of the production process aimed at improving product quality. There were many problems in this field that required mathematical methods and the power of mathematicians. One of them is the problem of product quality control and quality management in the production 
process. The issue of quality control of the manufactured product is as follows. N products have been produced and these products must meet the relevant requirements. For example, suppose that the diameter of the projectile does not exceed [D1, D2]. Otherwise, these shells will be unfit for firing. They also need to be accurate (target accuracy), otherwise it will be difficult to hit the target. The first problem is easy to solve, that is, the diameters of the projectiles can be measured and those that do not meet the requirements can be identified. But the second problem is more complicated, because you have to try shooting. But it doesn't make sense to try them all in shooting. This should be done by testing a small amount of product to determine if the entire batch of product is suitable or not. The proposed method to solve this problem is called the statistical method. This theory was developed by academic M.V. Ostrogradsky's work was first considered in 1848, and later in Tashkent, Professor V.I. Romanovsky and his students dealt with this issue. During the war, A.N. Kolmogorov and his students improved it [5. 56-61].

After the end of the war, it was discovered that similar research had been conducted by U.S. mathematicians. As a result of their work, it was estimated that billions were saved in the country during the war years. The same can be said of Soviet mathematicians and engineers [6. 9-15].

g) Academician TA Sarimsakov developed the homogeneous and asexual Markov chains in the 1940 s and their application to synoptic meteorology. In his research, he combined in-depth theoretical knowledge with specific practical issues. He applies probabilistic schemes of Markov chains to the study of synoptic processes in Central Asia. The result is important for the economy [7. 230].

h) A. Turing, the British mathematician who is considered the father of computer science, was one of the developers of the methods used by the Nazis to break the Enigma code. With the help of his method, they were able to read all the secret information written by the Nazis. He founded cryptanalysis [8.195].

It's been 75 years since the war ended. World War II turned out to be, first and foremost, a tank war, an engine race, so the more precise and thoughtful one's design ideas, the more the outcome of many battles was determined. The mathematicians of the former Soviet Union made a great contribution to the recovery and development of the national economy. During the war, under very difficult and unbearable conditions, the development of theoretical mathematics was observed.

To date, there are no complete descriptions of how mathematicians served for the front, for victory, and how their research served to improve the weapons used in battle.

And we must never forget the heroism of the people in the great victory, not only because of the heroism of the war veterans, but also because of the improvement of military equipment with the hands of workers, engineers and scientists.

\section{Conclusion}

In short, the use of such materials in the educational process helps students to understand that mathematics is not a science of dry numbers and figures, but a history, a science related to the fate of mankind, mathematics is a science related to all sciences. It helps to explain that learning is a necessity, that mathematical knowledge is always needed no matter what we do. 
Introducing students to the scientific and spiritual riches of humanity through the example of the history of mathematics will also help them better understand the concepts and methods being studied and see how they can be applied to other areas of science and practice. The use of various forms of disclosure of historical and mathematical content helps to develop both cognitive and professional interest in science, creating additional situations that ensure that the acquired knowledge is of personal importance.

\section{References}

1. Akmalov A. The use of historical data in the teaching of mathematics. Tashkent: Science, 2005. -p. 56 ; Malykh A. E., Pestereva V. L. Use of historical information in teaching mathematics. Yaroslavl Pedagogical Bulletin -2011-No.3-Volume II

2. Pirogov I, Tulina I. Mehmat Moscow State University during the Great Patriotic War // Quantum. 1980. No5. -p. 10-17. (kvant.mccme.ru)

3. Kordemsky B.A. Great lives in mathematics. Moscow: Education, 1995. -p. 192

4. https://securityintelligence.com/what-a-wwii-mathematician-might-see-whenlooking-at-your-critical-it-assets/

5. Gnedenko B.V. Mathematics and defense of the country. // Mathematics at school. 1978. No. 2. -p. 56-61.

6. Gnedenko B.V. Mathematics and mathematics in World War II. // Quantum. 1985. №5. -p. 9-15.

7. Sarimsoqov T.A. Comprehension. Tashkent: Fan. 1987.-153s .; Sarimsaqov T.A. The Devonlary says. Tashkent: Uzbekistan. 1989. -p. 230.

8. Stuart I. Significant figures: Life and discoveries of the great mathematicians. Per. from English - Moscow: Alpina nonfiction, 2019. -p. 195

9. Doniyorov, A. K., \& Karimov, N. R. (2020). An Incomparable Book of a Great Scholar. Bulletin Social-Economic and Humanitarian Research, (6), 63-71. 